\title{
Educando para atitudes sustentáveis em Escola Estadual de Guaíba/RS e comunidade do entorno
}

Tania Renata Prochnow

Karina A. Latorre Castro Damasceno

Maria Eloisa Farias

\begin{abstract}
Resumo
Este projeto objetivou sensibilizar a comunidade escolar de uma Escola Estadual de Ensino Fundamental no município de Guaíba/RS, para incentivar adoção de atitudes sustentáveis na prática diária, contribuindo com a despoluição do ambiente em que vive, valorizando o destino correto dos resíduos descartados e aumentando a conscientização em relação ao consumismo exagerado, aplicando a prática dos $3 R^{\prime} s$, possibilitando alternativas de economia ou de reaproveitamento dos recursos naturais. Enfatizou mudanças de pequenos hábitos, iniciando na escola, com a participação de alunos do Ensino Fundamental e da modalidade EJA promovendo, após, expansão para toda comunidade escolar e inclusão da comunidade do entorno da escola, utilizando metodologias lúdicas e práticas sustentáveis. Os resultados obtidos foram positivos, resultando em reflexão sobre práticas ambientais, a implantação de práticas de reciclagem e reutilização na escola e comunidade, contemplando a Educação Ambiental (EA) formal com a comunidade escolar e EA não formal com a comunidade do entorno.

Palavras-chave: Agenda 21 na Escola, Educação Ambiental, prática dos $3 R^{\prime} s$.

\section{Abstract}

This project aimed to sensitize the school community in a Basic Education State School in Guaiba/RS municipality, to encourage the adoption of sustainable attitudes in daily practice, contributing to the remediation of the environment in which he lives, valuing the correct destination of waste and discarded raising awareness regarding the excessive consumerism, applying the $3 R^{\prime} s$ practice, enabling saving alternatives or reuse of natural resources. Emphasized small habits changing, starting at school, with the participation of elementary school students and EJA modality promoting, after, the expansion to the entire school community and the inclusion of the community around the school, using playful methodologies and sustainable practices. The results were positive, resulting in reflection on environmental practices, implementation of recycling and reuse practices in school and community, contemplating the formal Environmental Education (EE) with the school community and non-formal EE with the surrounding community.
\end{abstract}

Keywords: Agenda 21 at School, Environmental Education, 3R's practice. 


\section{Introdução}

Respeitando o conceito de que mudanças de hábitos começam na educação e as ações de incentivo estão nas escolas, se faz necessário que se trabalhe com projetos de Educação Ambiental (EA) não somente em datas comemorativas, mas contemplando um processo contínuo e fortalecido. Pois, segundo Carvalho (2008) "ler" o meio ambiente "é apreender um conjunto de relações sociais e processos naturais captando as dinâmicas de interação culturais, sociais e naturais" (CARVALHO 2008, p. 86).

A proposta educativa que inspira este projeto é a de formar sujeitos capazes de compreender o mundo e agir de forma crítica com a intenção de capacitar a interpretação de sua complexidade e de sua constante transformação.

Naime cita que:

"A educação é a base para o desenvolvimento e a vida civilizada, pois através dela as pessoas têm subsídios para exigir seus direitos e cumprir os seus deveres, ou seja, as pessoas têm condições de desempenhar o seu papel de cidadão (2004 p.79)."

Ainda, no mesmo autor, encontramos que:

"A educação ambiental tem seu eixo fundamental na práxis de novas atitudes e relação aos problemas ambientais. ... Em outras palavras, é uma forma integra de ler a realidade e atuar sobre ela através de uma visão de mundo como um todo, não podendo ser reduzida só a um departamento, uma disciplina ou programa específico. Daí a necessidade de ligar ações multi e interdisciplinares à educação ambiental." (NAIME, 2004 p. 80).

Conhecendo a realidade da comunidade escolar, observa-se a necessidade de uma iniciativa de conscientização para a preservação do meio ambiente, com mudança de pequenos hábitos que visem sustentabilidade e contribuindo, ao mesmo tempo, com a despoluição e com a redução do consumo exagerado, visando agregar uma nova consciência de danos ambientais.

$\mathrm{Na}$ escola, o projeto foi realizado na forma interdisciplinar denominado "Agindo por um mundo sustentável", intencionando expandir a ideia de sustentabilidade incentivando os alunos a serem multiplicadores em suas famílias e na comunidade local.

Buscou-se introduzir, na população-alvo, uma preocupação permanente com os impactos ambientais e a busca de alternativas para solução de problemas, agregando a consciência de que se deve tratar com racionalidade os recursos naturais, instigando à novas mudanças. Soares et al (2004) ressaltam que: “Os problemas ambientais globais são, agora, de responsabilidade não mais de unidades isoladas (instituições, empresas, comunidades científicas ou governos), mas sim de toda a sociedade". 
Massine (2010) traça a relação meio ambiente, sustentabilidade e cidadania como temáticas inseparáveis, pois estas questões estão interligadas e presentes na Constituição Federal (1988) e na Política Nacional de Educação Ambiental (1999), tendo como foco central a conscientização ecológica.

Segundo Carvalho \& Moura:

"O surgimento da questão ambiental como um problema que afeta o destino da humanidade tem mobilizado governos e sociedade civil nas últimas décadas, todo o conjunto de práticas sociais voltadas para o meio ambiente tem se instituído tanto no âmbito das legislações e dos programas de governo quanto nas diversas inciativas de grupos, de associações e de movimentos ecológicos." (CARVALHO \& MOURA, 2008 p. 23).

E acrescentam, "A legislação desse conjunto de preocupações e práticas ambientais na sociedade contemporânea é o terreno fértil em que podemos ver surgir um sujeito ecológico".

Como descreve Massine (2010) a consciência ecológica que nasce com o ensino proposto pela educação ambiental, se mostra como um dos caminhos mais racionais e eficazes para se atingir uma ética realmente ativa.

A lei federal n6938 de 1981, instituiu a "Politica Nacional do Meio Ambiente" (PNEA), que aponta a necessidade da Educação Ambiental ser oferecida em todos os níveis de ensino. A constituição Federal do Brasil, promulgada no ano de 1988, estabelece, em seu artigo 225, que:

"Todos têm direito ao Meio Ambiente ecologicamente equilibrado bem de uso comum do povo e essencial a sadia qualidade de vida, impondo-se ao poder público e a coletividade o dever de defendê-lo para as presentes e futuras gerações" (BRASIL, 1988 p. 36).

As políticas nacionais que dizem respeito ao desenvolvimento da educação ambiental são ferramentas essenciais que se consolidam na pauta de sustentabilidade e envolvem a ética, alicerçando para uma consciência crítica da sociedade no exercício da cidadania.

“Desenvolvimento sustentável é desenvolvimento que satisfaz as necessidades do presente sem comprometer a capacidade de as futuras gerações satisfazerem as suas próprias necessidades" (CMMAD, 1987, p.44). Segundo Sachs (2008) o desenvolvimento sustentável se baseia em cinco pilares: o social, o ambiental, o territorial, o econômico e o político. Conforme Castelnou (2008), observando-se o modo de vida de comunidades tradicionais, constata-se que as sociedades verdadeiramente sustentáveis desenvolvem um conhecimento detalhado sobre o meio ambiente local e o assimilam à própria cultura, atuando abaixo da capacidade de suporte do seu ecossistema. 
Já o padrão de urbanização imprimiu às metrópoles ao menos duas fortes características associadas ao modo predominante de fazer "cidade". Estas apresentam componentes de "insustentabilidade" associados aos processos de expansão da área urbana, proporcionando uma baixa qualidade de vida urbana a parcelas significativas da população (GROSTEIN, 2001).

A sustentabilidade propõe que o consumo seja consciente, que se saiba comprar apenas produtos realmente necessários, posicionados numa postura ecológica.

Jacobi (2003) acrescenta: "A problemática da sustentabilidade assume neste novo século um papel central na reflexão sobre as dimensões do desenvolvimento e das alternativas que se configuram".

A EA, quando bem realizada, leva a mudanças de comportamento pessoal e a atitudes e valores de cidadania. A sociedade encontra-se familiarizada com o tema sustentabilidade e meio ambiente através da mídia, com a divulgação do tema nos noticiários. Ocorreu em 2012 a Conferência Rio+20, no estado do Rio de Janeiro, fato plenamente divulgado nos meios de comunicação. É inevitável que as escolas explorem o assunto, tornando se ícones de discussão e reflexão de temas atuais.

Libâneo defende uma educação ambiental clara e objetiva e explana a respeito afirmando que "A educação ambiental não pode ser apenas uma tarefa da escola, ela envolve ações práticas que dizem respeito ao nosso comportamento nos vários ambientes (na família, na escola, na cidade, na empresa etc.)". Assim é necessário aumentar os conhecimentos ambientais e modificar nossa relação com o ambiente, recusando o conceito de progresso baseado na capacidade de possuir mais objetos e bens de consumo, assumindo um modo de vida baseado na relação com a natureza e as pessoas do que com os objetos (LIBÂNEO, 2004).

Os PCN (Parâmetros Curriculares Nacionais) desenvolvidos pelo MEC (Ministério da Educação) fornecem orientações para os professores, propondo instrumentos de apoio pedagógicos, enfatizando a interdisciplinaridade e o desenvolvimento da cidadania entre os educandos, estabelecendo temas especiais que devem ser discutidos, em conjunto, nas disciplinas da escola; são os chamados temas transversais (BRASIL, 2001).

Com o auxílio dos PCN, o professor pode encontrar um horizonte de sugestões de como aplicar aulas diversificadas e interessantes, buscando enriquecer com informações científicas possibilitando bons resultados.

A Resolução № 2, de 15 de junho de 2012, que estabelece as Diretrizes Curriculares Nacionais para a Educação Ambiental, cita em seu Art. 6o que:

"A Educação Ambiental deve adotar uma abordagem que considere a interface entre a natureza, a sociocultura, a produção, o trabalho, o consumo, 
superando a visão despolitizada, acrítica, ingênua e naturalista ainda muito presente na prática pedagógica das instituições de ensino (BRASIL, 2012)."

Libâneo (2004) esclarece que o professor tem o papel insubstituível de provimento das condições cognitivas e afetivas que ajudarão o aluno a atribuir significados às mensagens e informações recebidas das mídias, das multimídias e formas diversas de intervenção educativa. No professor está a capacidade de introduzir os alunos nos significados da cultura e da ciência, por meio de mediações cognitivas e interacionais.

Percebe-se a necessidade de mais envolvimento participativo no que se refere à realização de projetos de EA (Educação Ambiental) nas escolas. Conforme dados retirados do Censo Escolar pelo Ministério da Educação (BRASIL, 2006), nas escolas da região sul; 76\% dos professores alegam não ter tempo para o planejamento e realização de atividades extracurriculares. "É necessário trabalhar a qualidade da Educação Ambiental nas escolas: formar educadores e educadoras atuantes em processos de busca de conhecimentos, pesquisa e intervenções educacionais cidadãs com base em valores voltados para a sustentabilidade social, ambiental, econômica, cultural e política".

Faz-se necessário cativar os alunos nas práticas educacionais em sala de aula para que as aulas sejam prazerosas e aproveitáveis. O professor deve possuir uma intencionalidade no que busca em seus alunos. Perrenoud (2000) acrescenta que, "nas situações aprendizagem, é necessário que o professor envolva os alunos em atividades de pesquisa, em projetos de conhecimento".

Seguindo esta linha, enfatizamos Morin (2004), que afirma que "o conhecimento progride não tanto por sofisticação, formalização e abstração, mas principalmente, pela capacidade de contextualizar e englobar".

Um método utilizado para trabalhar em escolas a sustentabilidade, é a prática dos $3 R$ (reduzir, reutilizar e reciclar) que tem o poder das palavras em conscientizar de forma clara e sucinta, e nada melhor do que o ambiente escolar para apresentar essa ideologia em todas as disciplinas do currículo escolar. Segundo o Fernandes (2007) "a eficácia de uma política norteada pela redução, reciclagem e reutilização, deverá reconhecer a solidariedade entre gerações, valorizando um território fomentador de qualidade de vida no futuro".

As estratégias de ensino facilitam o processamento de ensino e aprendizagem, gerando desafios, explicações, exemplos e/ou contra exemplos no decorrer das interações. Libâneo (2004) relata que a escola de hoje não pode se limitar a passar informações sobre as matérias e a transmitir o conhecimento do livro didático, ela é uma síntese entre a cultura experienciada que acontece na cidade, na rua, com os meios de comunicação etc. 
Também é importante que todos os professores estejam envolvidos na Educação Ambiental, pois a escola sempre foi considerada uma instituição privilegiada para a formação de cidadãos responsáveis e sensíveis em relação à questão ambiental.

Fundamentado nestes princípios, este trabalho foi desenvolvido junto a uma escola de ensino fundamental, onde procurou modificar a visão de alunos e de seus familiares em relação ao seu ambiente do entorno. Incentivou à adoção de novas atitudes relacionadas ao descarte correto de resíduos sólidos, separação de óleo de cozinha usado, pilhas e baterias, entre outros, destinando-os corretamente ou para o reaproveitamento, assim buscando contribuir na redução dos impactos aos recursos naturais.

\section{Vivências de atitudes sustentáveis na escola}

A Escola Estadual de Ensino Fundamental, onde foi realizado o projeto de Educação Ambiental, se localiza no município de Guaíba-RS, integrando a Região Metropolitana de Porto Alegre, situado na margem direita do lago Guaíba, contando com uma população de pouco mais de 95.000 habitantes, segundo o Censo de 2010 (IBGE, 2010).

Atende aproximadamente 250 alunos nos três turnos, distribuídos em turmas de $5^{\circ}, 6^{\circ}, 7$, $8^{\circ}$ e $9^{\circ}$ anos do ensino fundamental, no turno da manhã. À tarde atende a educação infantil com quatro turmas e a modalidade EJA (Ensino de Jovens e Adultos) com as turmas T3,T4,T5 e T6, no ensino noturno. A escola conta com 18 professores e 8 funcionários que atendem alunos de 3 a 4 bairros do município, sendo estes um público diverso em questões socioeconômicas.

O projeto teve início no dia 05 de junho de 2011, data comemorativa ao Dia do Meio Ambiente, em Escola Estadual de Ensino Fundamental, localizada na cidade de Guaíba-RS, com uma turma de $6^{\circ}$ ano, envolvendo 22 alunos, durante uma aula de Ciências. Em sequência, o projeto se expandiu para o todo o ensino fundamental e EJA, envolvendo aos poucos toda a comunidade escolar e a comunidade do entorno.

Conforme os PCN:

"Temas da atualidade, em contínuo desenvolvimento, exigem uma permanente atualização; e fazê-lo junto com os alunos é uma excelente oportunidade para que eles vivenciem o desenvolvimento de procedimentos elementares de pesquisa e construam, na prática, formas de sistematização da informação, medidas, considerações quantitativas, apresentação e discussão de resultados etc. O papel dos professores, como orientadores desse processo, é de fundamental importância. Essa vivência permite aos alunos perceber que a construção e a produção dos conhecimentos são contínuas e que, para 
entender as questões ambientais, há necessidade de atualização constante." (BRASIL, 1997, p.188).

O projeto foi desenvolvido com o objetivo de gerar conhecimentos para aplicação, práticos e dirigidos à solução de problemas específicos. Envolve verdades e interesses locais.

Como primeira etapa, foi realizada uma apresentação, em data show, com imagens representando ambientes sem impacto ambiental, em contraposição com imagens de grandes áreas urbanas poluídas e de paisagens degradadas, como forma de sensibilização de motivação dos alunos participantes.

Segundo Jacobi:

"Refletir sobre a complexidade ambiental abre uma estimulante oportunidade para compreender a gestação de novos atores sociais que se mobilizam para a apropriação da natureza, para um processo educativo articulado $e$ compromissado com a sustentabilidade e a participação, apoiado numa lógica que privilegia o diálogo e a interdependência de diferentes áreas de saber." (JACOBI, 2002, p. 191).

A seguir, houve reflexão e debate com os alunos da turma, sugerindo-se a elaboração de um documento propondo mudanças na escola, e uma campanha de conscientização da problemática ambiental, propondo ações sustentáveis aos colegas, pais e comunidade local. Conforme o PAMA (Parâmetros em Ação: Meio Ambiente):

"A principal função do trabalho com o tema Meio Ambiente é contribuir para a formação de cidadãos conscientes, aptos a decidir e atuar na realidade Socioambiental de modo comprometido com a vida, com o bem-estar de cada um e da sociedade, local e global. Para isso, é necessário que, mais do que informações e conceitos, a escola se proponha a trabalhar com atitudes, com formação de valores, com o ensino e a aprendizagem de habilidades $e$ procedimentos. Esse é um grande desafio para a educação." (BRASIL, 2001, p. 45).

Os alunos foram informados sobre da existência da Agenda 21, elaborada em reunião conhecida como Rio 92, que ocorreu no Brasil há 22 anos, na cidade do Rio de Janeiro. Foi discutida a importância do documento, o que serviu de incentivo para a elaboração do documento da turma.

Na etapa seguinte, foram elaborados cartazes de conscientização e preservação do meio ambiente e panfletos, distribuídos aos alunos, convidando-os a participar das atividades propostas pelo projeto agora intitulado "Agindo por um mundo sustentável". 
Os cartazes construídos foram colocados nos murais da escola para divulgar à toda comunidade escolar as iniciativas do projeto.

Durante a semana da divulgação iniciou-se uma campanha de coleta de óleo de cozinha usado, jornais, papelão, pilhas e baterias, com duração de dois meses, quando cartazes explicativos e recipientes coletores foram disponibilizados para toda a escola.

Visando o caráter interdisciplinar presente no projeto, os professores de matemática com os alunos do $6^{\circ}$ ano exploraram os valores de quantia, peso e tempo de recolhimento dos itens da campanha de coleta, elaborando tabelas e gráfico, pois:

$$
\begin{aligned}
& \text { "O educador deve estar munido de um conhecimento suficiente para } \\
& \text { desenvolver os conteúdos que se propõe. Para que a EA seja implementada é } \\
& \text { necessário que o educador saiba os conteúdos a serem inseridos na sua prática } \\
& \text { disciplinar. Após a escolha do conteúdo deve-se selecionar o referencial teórico } \\
& \text { e livros que discutam a temática a ser abordada, bem como a ideologia do } \\
& \text { ensino e do aprender" (HIGUCHI \& AZEVEDO, 2004, p.69). }
\end{aligned}
$$

Foram desenvolvidas, pelos alunos, pesquisas em sala de aula com questões de sustentabilidade e da prática dos 3R ("reduzir, reutilizar, reciclar"), utilizando meios eletrônicos. Após esta atividade, os alunos produziram panfletos sobre o tema, para serem distribuídos aos colegas de outras turmas, com a finalidade de investigar se em suas residências se pratica a separação dos resíduos para a coleta seletiva, indagando o que é feito com os materiais que não são utilizados. Esta ação foi estendida a professores e funcionários da escola, assim ampliando-se a abrangência, à comunidade local.

A partir deste momento, os demais professores da escola contribuíram com o projeto, incentivando os alunos a descartarem os resíduos nos locais adequados, trabalhando em suas aulas, nas diversas disciplinas, a importância da coleta seletiva, bem como os danos visuais e ambientais causados pelos descartes inadequados nas grandes cidades.

Os resíduos arrecadados durante a campanha foram vendidos a uma cooperativa de recicladores locais, gerando recursos financeiros que foram utilizados para a compra de soda cáustica, utilizada na fabricação de sabão ecológico com o óleo de cozinha coletado durante a campanha realizada na escola. A produção do sabão contou com a presença de todos os alunos do ensino fundamental, no turno da manhã.

Realizou-se uma atividade de "troca-troca" entre as turmas de $6^{\circ}, 7^{\circ}, 8^{\circ}$ e $9^{\circ}$ anos, que foram convidadas a participar. A atividade consistiu em trocas de materiais que estivessem em desuso para uns, mas que fossem reaproveitáveis para outros. Esta atividade realizou-se ao menos uma vez por mês, durante o restante do ano letivo. 
Foi também realizado um evento de apresentação de trabalhos dos alunos, onde a escola proporcionou a realização de uma oficina que reaproveitou material descartado para criação de utilitários, como porta objetos feitos de potes de sorvetes; o mesmo aconteceu no decorrer do projeto, onde os alunos confeccionaram jogos didáticos com tampinhas de leite, garrafas pet e caixas, que posteriormente foram utilizados, para recreação, em sala de aula.

Durante o período de execução do projeto, os alunos das turmas de $6^{\circ}$ e $7^{\circ}$ anos, visitaram uma empresa, localizada no município de Guaíba-RS, para conhecer a estrutura e a algumas práticas sustentáveis adotadas pela empresa.

O projeto desenvolvido na escola foi apresentado à comunidade, por alunos e professores participantes, na Câmara de Vereadores do Município de Guaíba.

Após a realização destas atividades, foi necessário coletar dados que indicassem os resultados alcançados. Foi elaborado um Instrumento de Coleta de Dados (ICD), na forma de um questionário estruturado com quinze questões referentes ao tema. Os ICD foram entregues para pais de um terço dos alunos de cada turma do ensino fundamental e do EJA da escola. As respostas coletadas foram tabuladas, sendo os dados estudados, apresentados e discutidos a seguir.

\section{Resultados e discussão}

A turma do 6 ano, da escola onde foi desenvolvido o projeto, diante das reflexões, adquiriu conhecimentos sobre os impactos ambientais causados pelo homem. $O$ projeto os estimulou ao ponto de produzirem um acordo documentado sobre o tema, baseado no modelo da Agenda 21, sendo uma das alunas indicada como relatora, onde foram propostos os compromissos assumidos pelos alunos objetivando um modo de vida mais sustentável tanto no ambiente escolar como fora do mesmo (figura 1). 


\section{E. E. Fundamental Cel Frudouci Lainck Esaala}

\section{Documento de lompromissar}

No dia 10 de Junho de 2011, os alunos da turma do bano em reflecãos das situnç̃os pridelemáticas da escala

e em verspito as mei ambiente de comum acordo decidem

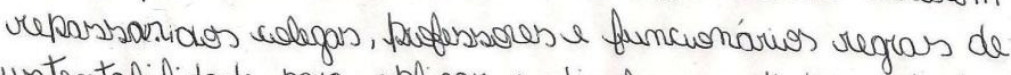
surstentalielidade para aplicar e disulegar a todos, jeitados a seguir

Eu me comprometo:

1- Jogor $\theta$ lixo nos lixeiros adequados 2- Rolhas do caderno.

3- Z elar pela limpera das salars e do pátio.

5- Veritando o desperdício de alimentos.

vempre fechadars. b- Ao ssair das salass nerificar se as luzens estão apa-
gadars.

7 - Puidar do material escalar cono lirros da escala,

Classtets, cadeivas sutrots.

8 - Diruelgar a píatuca dols 3hs e também puatica - los

9- Ser conciente e rersponsárrel não vís not escala, nots im cara e na comunidade a vespeeto do descarte de versidwors.

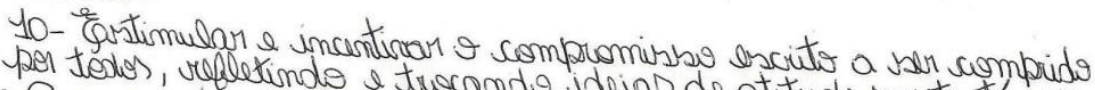
* Procurando indo e trocando ideias de atetude surstentarreis. da turma conclu segr tiodas sregrats a aluna representante therma conclui iste dicumento absinado.

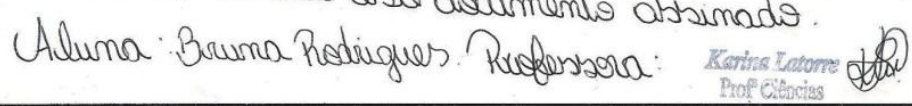

Figura 1 - Documento, visando a sustentabilidade, elaborado pelos alunos do $6^{\circ}$ ano.

A Comissão de Meio Ambiente e Qualidade de Vida na Escola, em sua publicação "Construindo a Agenda 21 na Escola" (BRASIL 2007), indica a importância do estabelecimento de compromissos em relação ao ambiente:

"A Agenda 21 é um programa de ação para todo o planeta. Ela tem 40 capítulos, que mexem com tudo, do ar ao mar, da floresta aos desertos; propõe até estabelecer uma nova relação entre países ricos e pobres. Na Agenda 21, como em qualquer agenda, estão marcados os compromissos da Humanidade 
com o Século XXI, visando garantir um futuro melhor para o planeta, respeitando-se o ser humano e o seu ambiente." (BRASIL, 2004, p.15).

Ao construírem a sua "Agenda 21", os alunos evidenciaram a assimilação das propostas da educação ambiental para a sustentabilidade, pois conforme Sorrentino et al (2005):

"A educação ambiental, em específico, ao educar para a cidadania, pode construir a possibilidade da ação política, no sentido de contribuir para formar uma coletividade que é responsável pelo mundo que habita. ... A educação ambiental entra nesse contexto, orientada por uma racionalidade ambiental, transdisciplinar, pensando o meio ambiente não como sinônimo de natureza, mas uma base de interações entre o meio físico-biológico com as sociedades e a cultura produzida pelos seus membros. " (SORRENTINO et al, 2005, p.287 e 289).

Após a elaboração do documento, o projeto se expandiu a toda comunidade escolar, através das divulgações e das campanhas apresentadas por estes alunos, com o intuito de convidar todos a participarem das novas práticas sustentáveis propostas para a escola.

Como parte do projeto, a campanha de descarte dos resíduos sólidos mobilizou a todos por dois meses, e rendeu uma quantia simbólica de $\mathrm{R} \$ 30,00$ reais, resultantes da venda de papel e papelão para uma cooperativa de reciclagem da comunidade local (tabela 1). Os resíduos vendidos continham: revistas, livros e cadernos velhos, folhas e jornais usados, caixas de leite e caixas de utensílios.

As pilhas e baterias recolhidas, que não podem ser vendidas, foram repassadas a prefeitura municipal de Guaíba para o descarte adequado; o óleo de cozinha coletado foi reaproveitado na produção de sabão na própria escola.

Tabela 1 - Material coletado no período da campanha de coleta de resíduos sólidos.

Material coletado

Papel

Papelão

Óleo de cozinha

Pilhas e baterias usadas
Quantidade arrecadada

30 quilos

15 quilos

10 litros

2 garrafas PET de 2 litros

cheias
Valores obtidos

$\mathrm{R} \$ 15,00$

$\mathrm{R} \$ 15,00$ 
Durante a coleta de resíduos os alunos tabularam as quantias arrecadadas e trabalharam com os dados nas aulas de matemática; foram também tabulados dados sobre a prática dos $3 R$ aplicadas pela comunidade escolar. Com os dados tabulados foram realizados exercícios de elaboração de tabelas e gráficos (figuras 2).

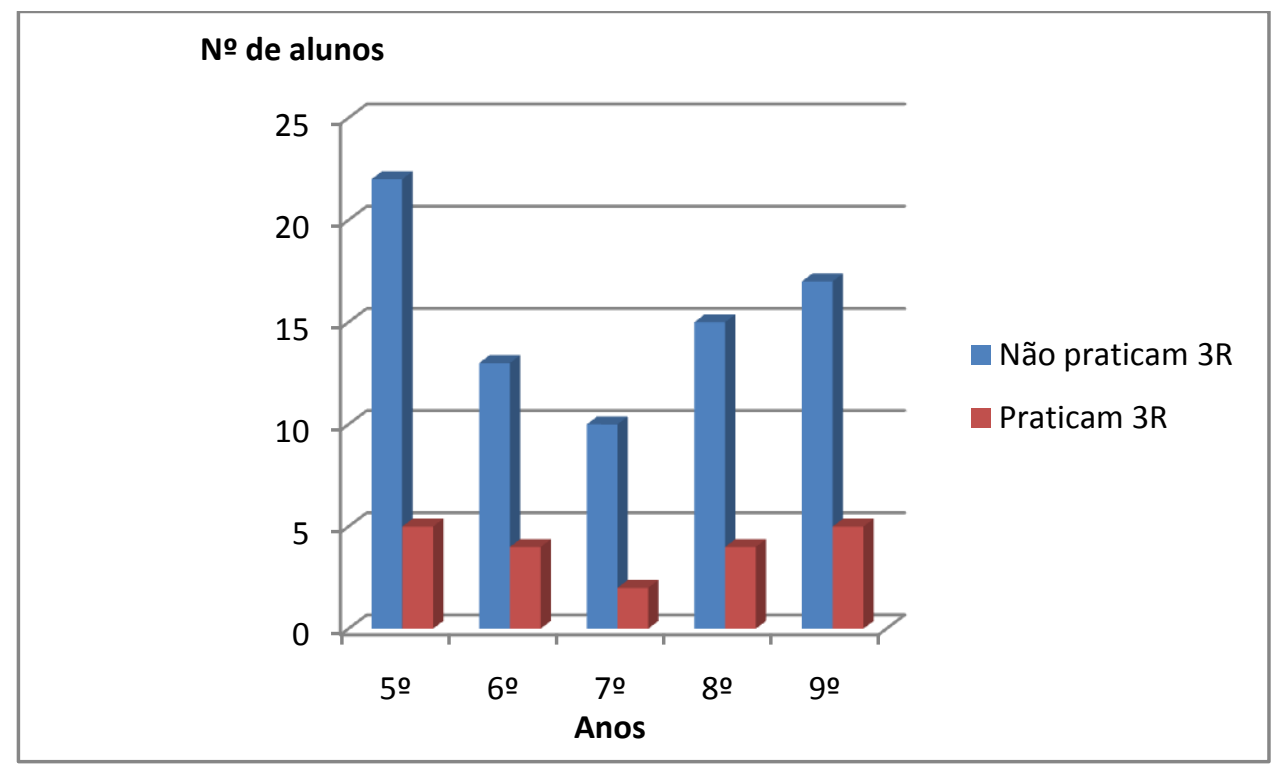

Figura 2 - Exercícios de representação gráfica realizados pelos alunos, sobre a prática dos $3 R$, por turmas da Escola.

Utilizando a pedagogia dos 3R's associada à ideia de mudança de comportamento, no que compete especialmente aos órgãos governamentais, as escolas e a outros grupos sociais, acredita-se que estudos desse caráter, possam induzir esses atores sociais a se posicionarem ou refletirem sobre a realidade apresentada, e assim buscarem mudanças a partir de novas diretrizes de gestão, que promovam resultados mais positivos para os setores e para as localidades envolvidas (MACEDO et al, 2012).

Na experiência de fazer sabão, realizada no pátio da escola; os alunos revelaram grande interesse e curiosidade. Além dos alunos do 60 ano, foram convidados todos os alunos do turno da manhã, onde todos puderam ver e/ou ajudar na fabricação do produto (figura 3). Inicialmente, foram dadas explicações sobre as reações químicas que ocorrem quando se misturam os reagentes, enfatizado os conhecimentos científicos desta prática.

A compra de soda cáustica utilizada e do filme PVC para embalar o sabão, foi realizada com o valor arrecadado com a venda dos materiais coletados na Campanha de Coleta de Resíduos (tabela 1). 
Para fazer o sabão ecológico foram utilizados quatro litros de óleo usado coletados durante a Campanha, dois litros de água quente, um quilo de soda cáustica em escamas e $5 \mathrm{ml}$ de óleo aromático. O sabão produzido foi distribuído para professores, pais e comunidade local no dia das apresentações de trabalhos dos alunos.

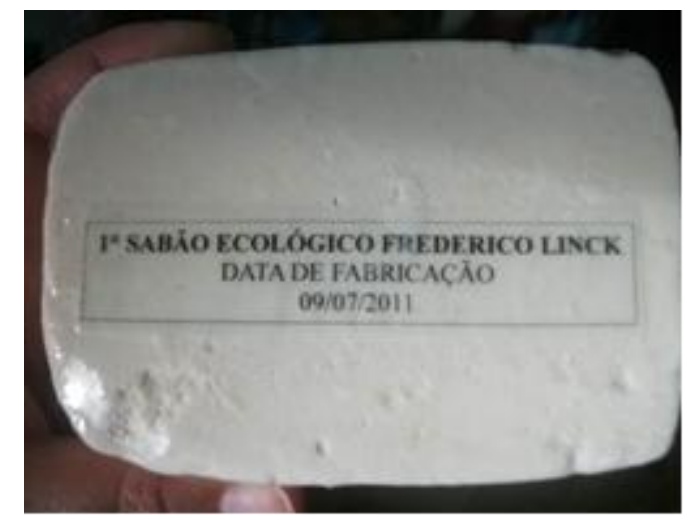

Figura 3 - Sabão produzido na Escola, com óleo de cozinha utilizado coletado na Campanha de Coleta de Resíduos.

Os eventos que ocorreram com a atividade "Troca-troca", até o final do ano letivo de 2011, proporcionaram uma grande integração da comunidade escolar; os alunos aguardavam, com expectativa, as datas agendadas para a prática de troca de seus materiais em desuso, por outros de seu interesse.

Nesses encontros, que se realizaram uma vez ao mês, os alunos trouxeram diversos CDs, DVDs, livros, brinquedos, roupas, sapatos e pequenos objetos diversos para serem trocados com seus colegas.

Houve também o evento oficinas didáticas, organizadas pelos professores de artes, e de apresentação dos trabalhos na escola. No evento, os alunos foram convidados a participar de uma oficina que visou o reaproveitamento de materiais descartados para criação de utilitários, como porta objetos, feitos de potes de sorvetes. No mesmo evento, os alunos apresentaram jogos didáticos e materiais diversos confeccionados com sucatas no decorrer do projeto, tais como: jogo da memória e jogo de xadrez com tampinhas de leite, utilitários de garrafas pet, caixas e outros materiais.

Nestas oficinas houve a preocupação em não produzir utilitários que pudessem rapidamente se transformar em novos resíduos. Segundo Cavignato (2013), brinquedos com sucata devem ser úteis, caso contrário acabam quebrando com facilidade e, além disso, a reciclagem destes materiais pintados é mais difícil, gerando mais resíduos a partir da tentativa de reutilização. 
Para vivenciar a aplicação prática de atitudes sustentáveis, foi realizada uma visita com os alunos das turmas de $6^{\circ}$ e $7^{\circ}$ anos a uma empresa, localizada no município de Guaíba. Lá os alunos tiveram a oportunidade de conhecer a estrutura da empresa e algumas práticas sustentáveis adotadas pela empresa. Foram recebidos por monitores da empresa que apresentaram o tratamento interno de água e de esgoto, o deposito de materiais para descarte e os reaproveitamentos de materiais corretamente implantados; conheceram também o banheiro ecológico. No final da visita receberam material impresso de incentivo à educação ambiental, com a política ambiental da empresa.

O ponto, considerado culminante, do projeto ocorreu quando, a convite da Câmara de Vereadores do Município de Guaíba, os alunos apresentaram o projeto para a comunidade, no auditório da Câmara, fato que teve repercussão na imprensa local. Estiveram presentes cinco alunos representantes do $6^{\circ}$ ano, e as professoras de língua portuguesa e ciências. Os alunos, representando a turma, apresentaram com o auxilio da professora, o trabalho realizado na escola, com imagens fotográficas e mensagens de sustentabilidade produzidas em power point. Para este evento, a Câmara foi decorada com os cartazes de conscientização produzidos pelos próprios alunos.

Após a realização destas atividades, realizou-se a coleta dados, aplicando um Instrumento de Coleta de Dados (ICD) às famílias dos alunos, procurando investigar os resultados alcançados pelo projeto junto à comunidade do entorno. Os resultados quantitativos alcançados pela aplicação do ICD, que foi produzido na forma de um questionário com quinze questões referentes ao tema do projeto, sendo 7 quantitativas e 8 qualitativas, são apresentados na tabela 2. Os ICD foram entregues para pais de um terço dos alunos de cada turma do ensino fundamental e da EJA da Escola, totalizando 30 respondentes.

Houve uma boa receptividade por parte das famílias dos alunos quanto ao questionário aplicado para o levantamento de dados, que expuseram apenas a situação pós projeto, sendo considerada como falha metodologia a não aplicação de um ICD de pré sondagem que viabilizasse a comparação da evolução da relação comunidade/ambiente. A aplicação de um pré-teste permitiria uma análise estatística não paramétrica (teste de Mann-Whitney) para amostras de pequeno tamanho (FERNADES, 2010).

Apesar da divulgação do projeto pelos alunos junto às suas famílias, um terço dos entrevistados ainda não tem o hábito de separar os resíduos gerados para o descarte adequado, em suas residências. 
Tabela 2 - Resultados quantitativos das respostas obtidas com a aplicação do ICD

\begin{tabular}{|c|c|c|c|c|}
\hline & Questões do questionário aplicado aos pais & Sim & Não & Total \\
\hline & $\begin{array}{l}\text { Tens obtido conhecimento através de seu filho pelo } \\
\text { projeto que vem sendo aplicado na escola Agindo por } \\
\text { um mundo sustentável? }\end{array}$ & 30 & 0 & 30 \\
\hline 2. & $\begin{array}{l}\text { Acreditas que devemos modificar nossos hábitos em } \\
\text { relação da melhoria do nosso meio ambiente? }\end{array}$ & 30 & 0 & 30 \\
\hline 3. & $\begin{array}{l}\text { Tens o hábito de controlar o consumo de energia e } \\
\text { água na sua residência? }\end{array}$ & 29 & 1 & 30 \\
\hline 4. & . Já ouvistes falar pelo seu filho (a) a prática dos 3 R? & 29 & 1 & 30 \\
\hline 5. & $\begin{array}{l}\text { Tens o costume de separar o lixo produzido em sua } \\
\text { casa? }\end{array}$ & 20 & 10 & 30 \\
\hline 6. & $\begin{array}{l}\text { Conheces os danos causados no ambiente do descarte } \\
\text { de pilhas, baterias e lâmpadas fluorescentes? }\end{array}$ & 29 & 1 & 30 \\
\hline 7. & . Alguma vez já fizestes sabão caseiro? & 5 & 25 & 30 \\
\hline
\end{tabular}

As questões qualitativas evidenciaram uma confusão do conceito de sustentabilidade com preservação ambiental e coleta seletiva; porém, em todas as respostas houve ênfase na importância de contribuir para um mundo mais sustentável. Os pais manifestaram sua preocupação em separar materiais para os catadores do bairro e em doarem seus objetos em desuso; todos manifestaram interesse em participar da atividade "Troca-troca", realizada na Escola.

Foram preocupantes as respostas ao questionamento "O que fazes com o óleo usado?". A maior parte das respostas revela o desconhecimento sobre o impacto ambiental causado pelo descarte inadequado deste resíduo descartando-o com o lixo doméstico ou colocando na pia. Este fato enfatiza a necessidade de uma Educação Ambiental mais abrangente, que ultrapasse a fronteira da escola.

Todos os participantes consideraram o projeto desenvolvido extremamente importante, não apenas para a comunidade escolar, mas também para a comunidade do entorno.

Ao analisar as respostas obtidas com questionário aplicado aos pais, percebe-se que este projeto obteve bons resultados; constatou-se o entusiasmo e participação dos alunos e familiares. Os familiares relataram satisfação e entusiasmo dos filhos, mediante as atividades propostas e os resultados obtidos, gerando aspectos positivos em cada atividade realizada. 
Ao verificar a ação da prática dos $3 R$, os alunos não só a praticaram como também a divulgaram e estenderam aos pais e a comunidade.

Os alunos evidenciaram preocupação com as questões ambientais e demonstraram que as práticas de sustentabilidade os motivaram a refletir e agir de forma mais autônoma. Acreditam que a continuidade do mesmo possa contribuir de modo positivo para a mudança da postura ambiental da comunidade.

\section{Conclusões}

Com o desenvolvimento do projeto observamos que, para alcançar sucesso nas iniciativas de conscientização para mudanças de atitudes ambientais e para que estas se transformem em atitudes permanentes, as mesmas devem ser trabalhadas através de estratégias diversificadas de Educação Ambiental, apoio e divulgações constantes.

Como aspecto mais relevante do projeto, se destaca que o mesmo iniciou apenas com uma turma, teve uma ação crescente e se transformou num grande grupo, envolvendo durante todo o ano letivo: alunos, professores, funcionários, pais e comunidade local e contemplando objetivos da proposta educativa.

No final do projeto escolar foi possível constatar algumas mudanças de hábitos, porém este é um processo lento e contínuo que necessita de ações permanentes para que os indivíduos percebam a importância de vivenciar as novas práticas, tornando-as um exercício diário. Estas mudanças de hábito atendem os objetivos da educação ambiental descritos no parágrafo IV do Artigo 13 das Diretrizes Curriculares Nacionais para a Educação Ambiental, que objetiva “incentivar a participação individual e coletiva, permanente e responsável, na preservação do equilíbrio do meio ambiente, entendendo-se a defesa da qualidade ambiental como um valor inseparável do exercício da cidadania (BRASIL, 2012)".

Ainda é necessário que esta prática ocorra com caráter espontâneo e continuo e cabe à escola levar o projeto como um processo sem limites de tempo, para que realmente se consolide o aspecto sensibilizador, aperfeiçoando e renovando estratégias metodológicas, trabalhando com a visão ecológica para que os indivíduos envolvidos desenvolvam um novo modo de agir, adquiram novos hábitos e comportamentos em relação ao seu meio ambiente com pensamento crítico a respeito de atitudes sustentáveis.

\section{Referências}

BRASIL. Parâmetros Curriculares Nacionais: terceiro e quarto ciclos - apresentação dos temas transversais. Secretaria da Educação Fundamental. Brasília: MEC/SEF, 1997. 
BRASIL. Constituição da República Federativa do Brasil - Brasília, 1998.

BRASIL. Ministério da Educação, Secretaria da Educação Fundamental. Parâmetros em Ação Meio Ambiente na Escola de 5a a 8a série. Brasília, 2001.

BRASIL. Ministério da Educação. Censo Escolar 2006. INEP, Brasília, 2006.

BRASIL Ministério do Meio Ambiente, Ministério da Educação. Formando COM-VIDA, Construindo Agenda 21 na Escola. Brasília, 2007.

BRASIL - Ministério Da Educação, Conselho Nacional De Educação - Conselho Pleno - Resolução № 2, de 15 de junho de 2012, - Diretrizes Curriculares Nacionais para a Educação Ambiental. Brasília, 2012.

CARVALHO, I., MOURA, C. Educação ambiental: a formação do sujeito ecológico. $4^{\circ}$ ed. Editora Cortez, SP, 2008.

CASTELNOU, A. M. N. Por uma cidade sustentável. In: PARANÁ. Educação Ambiental. Curitiba, v. 3, 2008. p.55-62.

CAVIGNATO, D. - Análise do consumo sustentável na Escola de Educação Infantil Antônio José Mantuan - Revista do Instituto de Geociências - Geol. USP, Publ. espec., São Paulo, v. 6, p. 5-62, Agosto 2013.

CMMAD - COMISSÃO Mundial para o Meio Ambiente e o Desenvolvimento - Nosso futuro comum. Relatório elaborado para o Programa das Nações Unidas para o Meio Ambiente (PNUMA) - Rio de Janeiro, Fundação Getúlio Vargas, 1987.

FERNANDES, J. A. Urbanismo Sustentável: redução, reciclagem e reutilização da cidade. Revista da Faculdade de Letras - Geografia - Universidade do Porto II Série, Volume I, 2007. Disponível em: http://web2.letras.up.pt/ifilosofia/gfe/public space/docs/Urbanismo\%20sustentavel\%20pela\%20 reducao,\%20reciclagem\%20e\%20reutilizacao\%20da\%20cidade.pdf . acessado em 12 de julho de 2012.

FERNANDES, A.S.Q. A educação ambiental formal e não formal nas escolas portuguesas : duas propostas de intervenção no Ensino Básico - Tese de Doutorado - Universidade Aberta, Portugal. Disponível em https://repositorioaberto.uab.pt/request-item?handle=10400.2/1463\&bitstream$\underline{i d=6907 .}$.

GIL, A. C. Como elaborar projetos de pesquisa. São Paulo: Editora Atlas, 1991.

GROSTEIN, M. D. Metrópole e Expansão Urbana - a persistência de processos "insustentáveis". São Paulo em perspectiva, SP, 2001. 
HIGUCHI, M. I. G.; AZEVEDO, G. C. Educação como processo na construção da cidadania ambiental. BRASIL. Constituição. Brasília: Senado Federal, 1988. Revista brasileira de educação ambiental. Brasilia 2004.

IBGE Censo Populacional 2010. Instituto Brasileiro de Geografia e Estatística - disponível em: http://www.censo2010.ibge.gov.br/

JACOBI, P. Educação ambiental, cidadania e sustentabilidade - Cadernos de Pesquisa, n.118, p189-205, São Luiz, MA, 2003.

LIBÂNEO, J. C. Organização e gestão da escola teoria e prática. $5^{\circ}$ ed. Editora Alternativa, 2004.

MACÊDO, D.A., OLIVEIRA, R.V.N., MARACAJÁ, K.F.B. - Atitudes responsáveis para um planeta sustentável: os 3 r's do consumo consciente - Revista Querubim - Ano 08 № 16 v.2 - 2012, pp 30 a 39.

MASSINE, M. C. L. Sustentabilidade e educação ambiental - Considerações acerca da política nacional de educação ambiental - A conscientização ecológica em foco. Trabalho publicado nos Anais do XIX Encontro Nacional do CONPEDI, Fortaleza - CE, Junho de 2010.

MORIN, E. A cabeça bem-feita - Repensar a reforma reformar o pensamento. $10^{\circ}$ edição RJ: Bertrand Brasil, LTDA, 2004.

NAIME, R.; GARCIA, A. C. A. Percepção ambiental e diretrizes para compreender a questão do meio ambiente. Editora: Feevale Centro Universitário, Novo Hamburgo, RS, 2004.

PEDRINI, A. G. Metodologias em Educação Ambiental. Editora Vozes, Petrópolis RJ, 2007.

PERRENOUD, P. 10 novas competências para ensinar - tradução Patricia Chittoni Ramos Editora Artimed AS.2000.

SACHS, I. - Desenvolvimento Includente, Sustentável, Sustentado. Ed.Garamond, Rio de Janeiro, 2008.

SORRENTINO, M., TRAJBER, R., MENDONÇA, P., FERRARO JUNIOR, L.A. - Educação ambiental como política pública. - Revista Educação e Pesquisa, São Paulo, v. 31, n. 2, p. 285-299, maio/ago. 2005.

Tania Renata Prochnow - Professor-pesquisador do Programa de Ensino de Ciências e Educação Matemática - PPGECIM - Universidade Luterana do Brasil - ULBRA/Canoas.

E-mail: taniapro@gmail.com

Karina A. Latorre Castro Damasceno - Pós-graduada em Ciências da Natureza Aspectos Transversais e Interdisciplinares Química e Física Universidade Luterana do Brasil ULBRA/Canoas.E-mail: karinalbg@yahoo.com.br 
Maria Eloisa Farias - Professor-pesquisador do Programa de Ensino de Ciências e Educação Matemática - PPGECIM - Universidade Luterana do Brasil - ULBRA/Canoas. E-mail: mariefs10@yahoo.com.br 